\title{
The Role of Enterprise Risk Management (ERM) \\ Using ISO 31000 for the Competitiveness of a \\ Company That Adopts the Value Chain (VC) Model and Life Cycle Cost (LCC) Approach
}

\author{
Dr. F. Antonius Alijoyo ${ }^{1}$ and Stefiany Norimarna ${ }^{2, *}$ \\ ${ }^{1}$ Dr. F. Antonius Alijoyo, Parahyangan Catholic University, Indonesia \\ ${ }^{2}$ Stefiany Norimarna, Center for Risk Management and Sustainability, Indonesia \\ stefiany.norimarna@crmsindonesia.org
}

\begin{abstract}
This paper discusses a conceptual review on how Enterprise Risk Management (ERM) plays a role in the competitiveness of companies that adopts the Value Chain (VC) model and Life Cycle Cost (LCC) approach. A literature review was conducted over some selected papers. The result shows that ERM is critically and fundamentally required to have an effective VC model and the practice of the LCC approach. Further, some discussions with practitioners in Indonesian listed companies gave a result that affirmed such conceptual review in a practical environment. The results lead to the recommendation that ERM should be a pre-requisite before the value adoption chain model and LCC approach by a company. This paper, however, is without the field research, and therefore, an empirical study is strongly recommended to confirm the conclusion of this conceptual review and to understand the critical key success factors in building or establishing an effective interlink between ERM, VC, and LCC.
\end{abstract}

Keywords: Value Chain, Life Cycle Cost, Enterprise Risk Management 


\section{3rd International Conference on BUSINESS,}

MANAGEMENT AND FINANCE

11-14 March, 2021

OXFORD, UNITED KINGDOM

\section{Introduction}

Companies need to ensure their business processes are integrated, efficient, and effective to create and protect the organization's value. In pursuing such an attempt, many companies adopt a value-chain (VC) model and life cycle costing (LCC) approach for their competitiveness.

A VC model is a business model that describes the full range of activities needed by an organization to create a product or service. Value chains encompass the full range of activities and services required to bring products or services from their conception to sale in their final market locally, nationally, internationally, or globally (Kumar \& Rajeev, 2016).

A VC is a way to visually analyze a company's business activities to see how the company can create a competitive advantage for itself. The purpose of a $\mathrm{VC}$ analysis is to increase the effectiveness and the efficiency of an organization's business process so that a company can deliver maximum value for the least possible cost. The value chain mainly focuses on the market collaborating strategy, where it emphasizes the linkages between production and marketing activities of the products and services effectively and efficiently (Kumar \& Rajeev, 2016). On the other hand, LCC is an important economic analysis used to select alternatives that impact both pending and future costs. It compares initial investment options and identifies the least cost alternatives for an asset over its lifespan.

However, implementing the VC model and LCC approach are conditioned by a series of important risks and deserve attention as they could destroy the organization's value chain. Therefore, companies seeking the VC model optimization and the LCC approach workability need to systematically address and manage their enterprise-wide risks through integrated and coordinated activities, known as ERM (Enterprise Risk Management). One of the most widely used ERM references is ISO 31000 as an international standard of Risk Management. It provides three pillars of ERM i.e., Principles, framework, and process of managing risks for an organization (ISO, 2018).

This paper is a review at the conceptual level on how the role of ERM implementation could help organizations for competitiveness through the VC model adoption and LCC 


\section{3rd International Conference on BUSINESS,}

\section{OXFORD, UNITED KINGDOM}

approach, while affirmation from the practitioners is also gathered from several companies listed in Indonesia Stock Exchange (IDX).

\section{Methodology}

The research is made through a literature review, supported by focused group discussions with some scholars and interviews with selected respondents who sit at senior management of corporations listed in IDX.

The literature review is conducted over some papers of relevant topics to understand the ERM key principles and the framework core elements and critical aspects of the risk management process. The review is extended to see the relationship between those principles, framework, and process of managing risks to the concept of the VC model and LCC approach. Subsequently, the interim result is used as the discussion platform with some scholars to map out and understand the relationship between them and the underlying concept of the VC model and LCC approach. To confirm the theoretical relationship between ERM, VC, and LCC, some interviews are conducted to obtain the viewpoints of practicing board and senior management of several corporations.

\section{Literature review}

\subsection{Enterprise risk management (ERM)}

ERM is the leading approach to managing and optimizing risks, enabling a company to determine how much uncertainty and risk are acceptable to an organization. With a company-wide scope, ERM serves as a strategic analysis of risk throughout an organization, cutting across business units and department, and considering end-to-end processes. In adopting an ERM approach, companies gain the ability to align their risk appetite and tolerance with business strategy by identifying events that could leverage them to capitalize on the opportunities while managing its adverse effect and then developing an action plan to manage them (Alijoyo, 2020, p. 1).

A company could follow various ERM frameworks - all of which should define the essential components, suggest a common language, and provide clear ERM guidance. Besides, each implemented framework should also describe an approach for identifying, analyzing, responding to and monitoring risks and opportunities facing the enterprise 


\section{3rd International Conference on BUSINESS,}

(Alijoyo, 2020, p. 2). As further elaborated by Arena, Arnaboldi, \& Azzone (2011), the role of ERM falls into two critical characteristics, namely (1) the characteristics of comprehensiveness that covers every different risk categories, and (2) the integration characteristics orienting on the ERM role that encompasses every line of business, functional areas, and its influence within a company. Within this context, ERM coexists within the corporate governance scope that covers the role of the company's internal audit, internal control, and financial reporting (Hoyt \& Liebenberg, 2011; Spira \& Page, 2003). By design, it enables the company to cope with its internal control issues and bring an added value to the firm and all of its stakeholders.

Among the more widely known frameworks and/or standards, the related ERM definitions that they promulgate are COSO ERM Framework (COSO) and ISO 31000 Risk Management Principles and Guidelines (ISO 31000).

\subsection{COSO ERM Framework (COSO)}

COSO (Committee of Sponsoring Organizations of the Treadway Commission) introduced the concept of Enterprise Risk Management Integrated Framework published in 2004 (COSO, 2004). It provided the ERM definition as follow "ERM is a process affected by an entity's board of directors, management and other personnel, applied in strategy setting and across the enterprise, designed to identify potential events that may affect the entity, and it manages risk to be within its risk appetite to provide reasonable assurance regarding the achievement of entity objectives". The definition reflects certain fundamental concepts whereby ERM is:

- A process, ongoing and flowing through an entity.

- Affected by people at every level of an organization.

- Applied in strategy setting.

- Applied across the enterprise, at every level and unit, and includes taking an entity- level portfolio view of risk.

- Designed to identify potential events that, if they occur, will affect the entity and manage risk within its risk appetite.

- Able to provide reasonable assurance to an entity's management and board of directors.

- Geared to the achievement of objectives in one or more separate but overlapping categories. 


\section{3rd International Conference on BUSINESS,}

This definition is purposefully broad. It captures key concepts fundamental to how companies and other organizations manage risk, providing a basis for application across organizations, industries, and sectors. It focuses directly on the objectives achievement established by a particular entity and provides a basis for defining enterprise risk management effectiveness. Further, in the latest COSO ERM Framework - Integrating with Strategy and Performance published in 2017 (COSO, 2017), it refers to the new focus that says "... enterprise risk management is not focused principally on preventing the erosion of value and minimizing risk to an acceptable level any longer. Rather, it is viewed as integral to strategy setting and the identification of opportunities to create and maintain value" (COSO, 2017).

COSO ERM framework has its own merits and legacy in the United States of America (USA) especially after the Sarbanes-Oxley Act was in effect. It originated from COSO Internal Control Framework published in 1992, which had been used widely throughout the world by many large organizations in managing their internal control framework. Some have seen the COSO ERM framework as the expansion of the COSO internal control framework, a thought that deserves on its standing especially from the accounting and auditing professionals' point of view.

As further explained by Lindberg \& Seifert (2011), the ERM of COSO builds upon eight components that cover the four management process (i.e., strategic, operations, reporting, and compliance). As such, these eight components are (1) internal environments, (2) objective setting, (3) event identification, (4) risk assessment, (5) risk response, (6) control activities, (7) information and communication, and (8) monitoring. Therefore, the company's organizational level that spans from its subsidiary to the entity-wide of the company is taken into account under the COSO ERM. As a result, this aids the company to broaden its business knowledge and core strategies, build a healthy relationship between the company directors and the management executives, expand the company's knowledge on its organizational risks, and last but least, build a solid communication and facilitation capabilities of the company (Frigo \& Anderson, 2011).

\subsection{ISO 31000 Risk Management - Guidelines (ISO 31000)}

ISO 31000 was published by the International Organization for Standardization (ISO). The initial version was issued in 2009, and the second version was published in 2018. It defines the risk management process as "coordinated activities to direct and control an 


\section{3rd International Conference on BUSINESS,}

organization concerning risk". It also defines the risk management framework as "a set of components that provide the foundations and organizational arrangements for integrating, designing, implementing, evaluating, and improving risk management throughout the organization" (ISO, 2018).

ISO 31000 as an International Standard, gains a very wide acceptance in many countries and large corporations (Alijoyo, 2020, p. 4) as it is practical and business-oriented. It consists of three components: the principles, framework, and process of managing risks. Therefore, ISO 31000 captures ERM as an integrated way of managing risk rather than simply a framework of ERM.

ISO 31000 further states that risk is the effect of uncertainty on objectives. Managing risk is therefore dealing with the effect of such uncertainty hence increasing the likelihood of the company achieving its objective. Purdy (2010) states that managing risks orients on the optimization process gravitates in increasing the likelihood of realizing and fulfilling the company's objectives. This statement is in line with the core principle of ISO 31000 i.e. create and protect value.

Furthermore, its universal characteristics make them applicable for any type of organization, public or private, large-size corporations or small-size corporations. And yet, it is built not from the drive of being compliant to certain regulations, but more on addressing the uncertainty of business challenges and how to deal with them (Alijoyo, 2020, p. 4). Some have seen ISO 31000 is developed from the AUS/NZS 4360 Risk Management Standard originating from Australia, especially in the part of 'risk management processes. It is true, but ISO 31000 is much more comprehensive, systematic, and universal. Also, Dali \& Lajtha (2012) enforced the benefits of the simplicity of implementing the ISO 31000 framework within the company and the robustness of the framework, which stated that ISO risk management process is made under the context of elaboration rather than strictness. Hence, the ISO 31000 has its advantages in comparison to the other risk management standard.

Below is the architecture of ISO 31000 which describes its three elements: principles, framework, and process of risk management. Those three elements would be further explored regarding its relationship with the VC model and LCC approach. 


\section{3rd International Conference on BUSINESS,}

\section{MANAGEMENT AND FINANCE}

\section{OXFORD, UNITED KINGDOM}

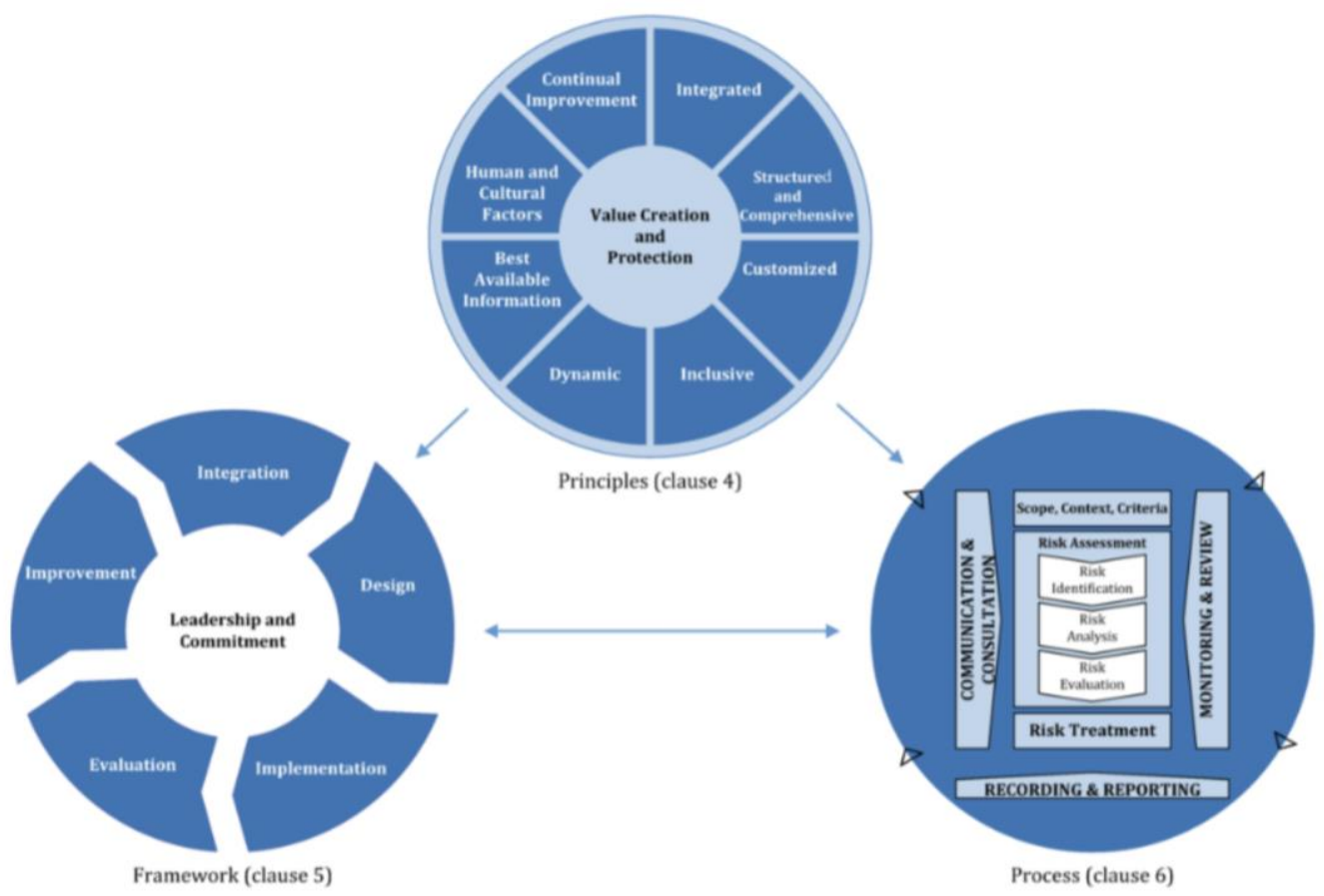

Source: ISO 31000:2018

The architecture starts with the core principle and eight underlying inter-related principles as the foundation for the organization. This will create and protect the organizational value through building leadership and commitment to implement organization-wide risk management, known as enterprise risk management or ERM. The leadership and commitment role is required to construct the effectiveness of the organization's risk management framework. A committed leader could help the company integrate, design, implement, evaluate, and improve the risk management framework.

Once the framework for managing risk has been determined and exercised appropriately, the process for managing risk could be carried out through several steps. It starts from communication and consultation with the stakeholders, establishing the scope, context, and criteria of risk assessment as well as risk treatment, monitoring and review, and recording and reporting. 


\section{3rd International Conference on BUSINESS,}

MANAGEMENT AND FINANCE

\section{OXFORD, UNITED KINGDOM}

\subsection{Value Chain (VC) and Enterprise Risk Management (ERM)}

Michael Porter was the first person who introduced the term "Value Chain" (VC) in his book Competitive advantage: Creating and Sustaining Superior Performance (Porter, 1998). He defines it as a representation of a firm's value-adding activities, based on its pricing strategy and cost structure. The ability of any firm to understand its capabilities and the customer needs is crucial for a competitive strategy to be successful. Since its introduction, VC is used throughout the world for nearly 30 years.

VC model is a powerful tool for disaggregating a company into its strategically relevant activities to focus on competitive advantage sources, that is, the specific activities that result in higher prices or lower costs. A company's value chain is typically part of a larger value system that includes companies either upstream (suppliers) or downstream (distribution channels), or both. This perspective about how value is created forces managers to consider and see each activity not just as a cost, but a step that has to add some value increment to the finished product or service (Porter, 1998).

The first steps in conducting the value chain analysis are breaking down the key activities involved in the framework. The next steps are to assess the potential for adding value through the means of cost advantage or differentiation. Finally, the analyst needs to determine the strategies that focus on those activities to enable the company to attain sustainable competitive advantages (Kumar \& Rajeev, 2016).

The profitability of a firm depends on how effectively it manages the various activities in the value chain; the price that the customer is willing to pay for the company products and services exceeds the relative cost of the value chain activities. Value chains encompass the full range of activities and services required to bring products or services from their conception to sale in their final market locally, nationally, internationally, or globally. The value chain includes producers, inputs suppliers, operations, processors, retailers, and buyers (Kumar \& Rajeev, 2016).

The value chain mainly focuses on the market collaborating strategy, where it emphasized the linkages between productions, marketing, etc., activities of the products and services effectively and efficiently. Vertical alignment is also an important aspect where companies connect one end of the primary activities up to the last end of the supportive activities, at each stage of the products which increases value (Kumar \& Rajeev, 2016). Therefore, to enable organizations to apply the Value-Chain model, they 


\section{3rd International Conference on BUSINESS,}

need to understand the demand dynamic on one hand and the cost-behavior on the other hand.

The demand dynamic is reciprocally linked to the value creation perceived by the customer, not only from the end product or services provided by the organization but also from the business processes series that produce customers' experiences. O'Donnell (2005), the critical performance factor of a company's value creation is information. In this case, it is about the information regarding the customers' demand for the company's product and how it affects the company's business process. Since the demand dynamic contains uncertainties, it consequently brings some potential risks for the organization in achieving its objectives of value creation.

While the generations naturally influence the demand dynamic, it is also shaped out tremendously by the revolutionary effect of Information and Communication Technology (ICT) advancement. As a result, younger generations - the future market, - bring different value metrics that are more sensitive to the process experiences rather than just to the goods or services pricing they consume. Furthermore, any business process that indirectly or directly impacts either positively or negatively on their experiences will affect the value perceived by them. Following this context, in establishing a data-driven company that incorporates ICT within its value creation, it needs to enhance its risk governance structure that involves the customers' information along with the company's due diligence process (Boyson, 2014). Accordingly, the value creation through ICT is not only limited to delivering value to the customers through the company's services and product but also includes the information of the company's customers security since the information technology risk degree and the cyber security needs are increasing with the advancement of technology that has taken place.

Therefore, it is a challenge for the organization to capture the dynamic of their future demand and assure their business processes catch up to the expected value perception pinpoint through customer experiences created. The value generated through the value chain is not only measured by currency but also by perception. For instance, if our organization uses a third party to deliver our product, then the third party's reputation should be considered whether it adds value or otherwise. If their reputation is good, an organization could expect a positive value creation and vice versa if their reputation is bad. 


\section{3rd International Conference on BUSINESS,}

The value chain model's design and execution need to address any effect of uncertainty on the respective business process objectives. By definition, risk (ISO 31000) is the uncertainty effect on the objectives, and therefore, an organization should address, identify, analyze, evaluate, and treat the risks if necessary to maintain them at a manageable level in achieving those objectives. Trends such as outsourcing, far sourcing, offshoring, just-in-time production, and consumer-driven production have increased the supply chains complexity. Complexity increases uncertainty and raises risk exposure. Increased risk exposure is also the consequence of increasing demand volatility, unprecedented technological changes, and globalization of production, making supply chains more susceptible to changing environmental and political contexts in different countries. With multiple actors, processes, products, linkages, and locations, the presence of risk factors is an inherent element of supply chain operations (Calatayud, 2017).

The organization also needs to conduct a risk management process referred to by ISO 31000 as "coordinated activities to direct and control an organization with regard to risk" (ISO 31000). The standard also defines the risk management framework as "a set of components that provide the foundations and organizational arrangements for integrating, designing, implementing, evaluating, and improving risk management throughout the organization".

Therefore, by implementing ERM based on ISO 31000, the organization would be able to define their risk context from the strategic objectives level of their value chain model down to the operational objectives that consist of their core business processes' objectives and the supporting business processes. Once the context has been established, they could build the risk management framework and process accordingly. Although risk management will not provide any guarantee of success, it would increase the probability for the organization to achieve their objectives, hence their success. If their objectives are about to increase their competitiveness, then risk management becomes fundamental and critical as it would increase the probability of success to gain competitiveness.

\subsection{Life Cycle Cost (LCC) and Enterprise Risk Management}

Although life cycle costing (LCC) is well-established in theory and practice, little is known about the conditions of its adoption and its impact on the achievement of costmanagement goals. The paper discusses the Life Cycle Costing (LCC) advantages and disadvantages and the challenges of implementation, requiring the role and support of 


\section{3rd International Conference on BUSINESS,}

\section{MANAGEMENT AND FINANCE}

\section{OXFORD, UNITED KINGDOM}

enterprise risk management (ERM).

Life Cycle Costing is the costing method that includes all costs over product life cycle to estimate the total product revenue and costs in life span to make a decision. The company wants to make a profit in the long term, not only one or two years, so tracking each product's profit is very important. Life cycle costing will calculate the costs and revenue per product lifespan, so the top management can make a precise decision to ensure its long-term profit. The cost will include everything from research and development (R\&D) production and discontinuing production. Naturally, As shown in the research conducted by Korpi \& Ala-Risku (2008), the purpose of LCC is oriented on the trade-offs between the company's product and designs, which specifically for the aim of comparison and optimization. Therefore, it can be said that there are some differences in the purpose of LCC due to various types of industries and the company itself.

Below is the illustration of a product life cycle graph as the base to figure out the revenue and its cost behavior.

Figure 1. Product life cycle

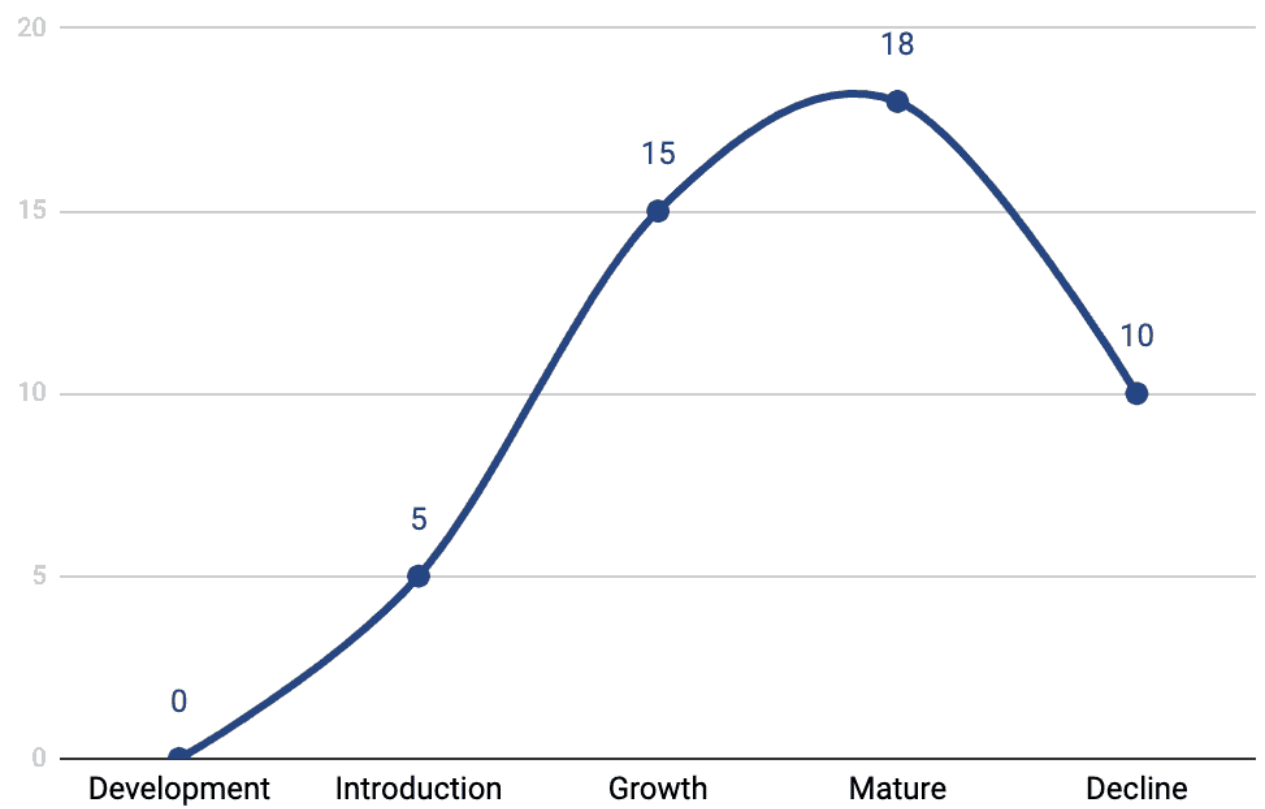

Source: https://accountinguide.com/life-cycle-costing/ 


\section{3rd International Conference on BUSINESS,}

Development: The stage when the company tries to do market research on a new product to know customer needs, their requirements, and competitor product's features. At this stage, there is not any revenue yet, only the cost that incurs.

Introduction: The stage when the company launched the new product into the market. There will be a huge marketing campaign to promote and advertise to the target customer. It may be some revenue with very high marketing expenses during this time.

Growth: The stage when the sale will start to increase and the marketing expenses will begin to decrease as the customers already aware of the company's product. It is the time that a sale starts to generate, and the product begins to make a profit.

Mature: The stage when the demand for the product will stop increasing and reaching its peak period. It is a time when most sales are made, the most profitable period. The company will try to extend this period as long as possible to maximize the profit.

Decline: Sooner or later, the demand will decline as the features are outdated, new substitute products, or a better choice from the competitors. The profit will start to decrease, or it stops completely. The company has to decide to keep or stop production.

The company uses LC costing as early as possible, i.e. in the design stage when we decide to start the design of this new product or not. LCC captures costs that occur not only during the manufacturing stage but also in earlier and/or later stages of a product's life cycle. Because these costs are relevant to decisions that are made from an ex-ante perspective, firms are well-advised to consider them at an early stage (Knauer \& Möslang, 2018).

Most figures are the budget that the company receives from various sources such as market research, experience, and industry information. In this stage, it is the time when management has to decide to make this product or not. The management may have a few products to select for investment. Therefore, they choose the highest profitable product. Looking at the full life product helps us see the full picture rather than one or two year profit which could be misleading. As such within the context of estimating the company's LCC, Asiedu \& Gu (1998) explained that the reasons to consider are (1) determining the most efficient design in regards to the cost design in comparison to the set of available alternatives, (2) determining the cost of the design itself in regards to the budgetary purposes, and finally, (3) identifying the cost drivers for the changes in the design and 


\section{3rd International Conference on BUSINESS,}

\section{MANAGEMENT AND FINANCE}

\section{OXFORD, UNITED KINGDOM}

optimization purposes.

It is clear that there are some advantages (i.e., Table 1) of the use of LCC for companies; however, there are also some disadvantages (i.e., Table 2) whereby the company needs to deal with the associated risks of such disadvantages.

Table 1. Advantages of life cycle costing

The Advantages
of life cycle
costing

Full budget over Management will be able to look at the full budget, which covers the product life the lifetime of the product; all expenses and revenues are included.

More accurate cost per unit
While all the expenses since $R \& D$ up to the restoring cost include in the product, the profit per product will be more realistic than the traditional method.

Select the highest profitable product

Life cycle costing will enable the company to select the most profitable product to be made. It will help to maximize shareholder wealth as well as management performance. It also enables comparison from one product to another. The comparison annual profit is not enough because it ignores the $R \& D$ cost as well as the contingent cost that will occur after product life.

Redesign the product
Management may want to decrease the product cost when the life profit is too low. We can as the engineer to redesign the product by withdrawing some features to reduce cost. We can do this in the early stage when products are not mass-produced. On the other hand, management may redesign the product by adding new features to extend the product life, which will maximize the profit 


\section{3rd International Conference on BUSINESS,}

MANAGEMENT AND FINANCE

OXFORD, UNITED KINGDOM

The Advantages
of life cycle
costing

as well.

Encourage This method will enable the management to focus on the longmanagement to term future of the company rather than meet short term targets and have a long-term get high bonuses.

view

Involve the Contingency liability is most likely to ignore by other methods contingency beside the life cycle costing. It is a massive expense for the liability company. We are responsible for restoring the original state of the environment.

Source: https://accountinguide.com/life-cycle-costing/

Table 2. Disadvantages of life cycle costing

The

disadvantages of

Description

life cycle costing

Estimate only This method relies heavily on the estimation of revenue that receives from market research and past experience. If something is wrong with this sale figure, the whole system will not work. The product will decrease profit or even make lost to the company.

Not flexible when The life cycle expects the market to be precisely the same as our market change product to develop, produce, and sell to the market. But everything changes from time to time, and it will impact our productive life. 


\section{3rd International Conference on BUSINESS,}

MANAGEMENT AND FINANCE

11-14 March, 2021

OXFORD, UNITED KINGDOM

The

disadvantages of

Description

life cycle costing

Due to the trend, customers may need different products by the time we reach the market. Our product may be shorter as the competitor keeps inject a similar or better product into the market. With all these changes, the actual situation will be different from our expectations, and it will impact our strategic plan.

Source: https://accountinguide.com/life-cycle-costing/

If we look at the market today, the disruption to the existing practices has made many assumptions and estimates of companies dull, and the sudden or twisted changes of the market make the company's product obsolete much faster than estimated. As a result, despite the advantages of LCC, a company must have some indicators that help them understand the market dynamic better and its impact on their assumptions. These indicators, named KRI - Key Risk Indicators, enable an organization to take decisions and actions to put the company's on track before the risk become a problem or mitigate the problem when it occurs. Such KRI's effectiveness will only be possible to reach if the company applies enterprise risk management thoroughly as KRI is an output of the right risk management process and could be used as leading indicators for a company to respond.

Without proper risk management, the LCC will not be useful in the time of many uncertainties and risks, and therefore, it becomes crucial and fundamental to have ERM implemented thoroughly.

\section{Results and Discussion}

The literature review results in the ERM to be critically and fundamentally required to have a VC model effective, and likewise to the practice of LCC approach. This result is brought into an online-focused group discussion (FGD) where many post-doctoral accounting background scholars gather at a webinar titled "Value Chain, Life Cycle Cost, GCG for competitiveness". In parallel, a similar result is also used as a reference in interviewing practitioners in Indonesian listed companies. 


\section{3rd International Conference on BUSINESS,}

The focused group discussion put a high recognition and appreciation on the VC model and gave merits to the LCC approach. All participants positively support and clearly state that the VC model and LCC approach will not be fully realized if risk management is not in place. They also emphasized that under today's dynamic environment where uncertainties and volatilities are rising, enterprise risk management's role becomes more and very crucial to the success of an organization's strategy, including pricing strategy through VC model and managing cost through LCC approach.

These viewpoints of FGD are supported by the comments and thoughts of practicing senior management from various industries among other banking, insurance, manufacturing, infrastructure, and energy utilities. Around 20 listed firms of the Indonesia Stock Exchange (IDX) contributed their views and opinions, represented by their executive directors and/or corporate secretaries.

Some of them shared their experience forward whereby they must put risk assessment, i.e., risk identification, analysis, and Evaluation at any stage of LCC from development, introduction, growth, mature, and decline. They also emphasized further that the whole risk management processes as the ultimate objective of the VC model and LCC approach align with the ERM's i.e. Value Creation and Protection.

Below are six questions posed in the focused group discussion of more than 25 scholars and interviews with a senior executive of 20 listed corporations. Each question is presented together with its summarized respective answers from the interviewee who supports and positively affirms the result of the literature review and FGD.

\subsection{Results and Discussion of Question 1}

Question 1: In order to gain or sustain the competitiveness of the company, what is the current business model or approach(es) being used to support decision making to the company's pricing and/or costing strategy? How effective are they?

\section{The summarized answers of the FGD}

Most of them said that organization adopt their cost accounting based on their value chain analysis, and provide some risk-based scenarios or options to the marketing and/or sales team who will determine the pricing of the company's product and/or services. As such, it is very common that the VC model comes together with ERM both in concept and practices. This result is in line with the research of Anderson (2006) under the context of 


\section{3rd International Conference on BUSINESS,}

strategic cost management that shows that the company can increase its value proposition through a clear recording mechanism and defined boundaries of its company. Consequently, in relation to VC, strategic cost management, and ERM, it is clear that an optimized cost structure of a company can further align its strategic decision in enhancing its value creation process.

\section{The summarized answers of the interviews with practitioners}

The decision to set the product or services' pricing should reflect the value proposition balance that is ground from the pricing currency, consumers' value perception, and its respective supply chain cost. Along with the rising digital channel whereby cyber risks must also be considered, ERM becomes crucial as it helps decision-makers understand the risk factors, including cyber risk and its value chain, and manage all related risk from the beginning until the end of supply chain.

\subsection{Results and Discussion of Question 2}

Question 2: What is your opinion about using (VC) Value Chain model in the organization or your corporation? And also about the adoption of LCC (Life Cycle Cost) approach? How to keep them workable at its best?

\section{The summarized answers of the FGD}

Most companies adopt the VC concept although the terminologies are somewhat different. Likewise, the LCC approach is also used by most companies. The difference between one company to another is the depth and details of the analysis and the sophistication and digitalization of their platform to conduct such analysis. Even though the VC's terminologies between the companies are different, the primary definition of $\mathrm{VC}$ orients on the activities of problem-solving and decision-making. As pointed out by Stabell \& Fjeldstad (1998), the VC activities depend on the characteristics of the company and its industry; however, the general ideas that build the concept of $\mathrm{VC}$ remain the same, and it is oriented on the aspect of determining the problem at hand, solving the persistent problem, selecting the best solutions among the set of alternatives, executing the selected solution, and regularly controls and evaluates the impact of the chosen solution. In relation to the aspect of sophistication and digitalization, the creation, the chain, and the delivery of value are also affected by the inclusion of technology within the company process. Such context has been addressed by Alter (2008), it is shown that 


\section{3rd International Conference on BUSINESS,}

by including the aspect of ICT within the creation and the chain of the company's value, the companies are faced with the challenges of aligning the role of its ICT with the company's business process. Consequently, the LCC analysis level will be different by default when taken into account the aspect of ICT due to the different needs and values among the companies.

\section{The summarized answers of the interviews with practitioners}

The concept of Value Chain and the approach of LCC would not be workable if we could not identify and analyze the risk factors in the whole exercise. A contingency perspective should be embedded and the value at risk needs to be visualized to help marketing set / determine the company's product or services value proposition. In that sense, we need to consider risk management approaches in the whole exercise of VC and LCC. ISO 31000 or COSO ERM Framework is considered to make our integrated risk management work at least in the product/services costing/strategy.

\subsection{Results and Discussion of Question 3}

Question 3: Do you adopt ISO 31000 or COSO ERM for your enterprise risk management? If yes, would you please describe how it affects the way you set the pricing and manage the costing to be competitive? If no, would you please tell what ERM reference (either standard or platform or framework) that you currently use?

\section{The summarized answers of the FGD}

Definitely, organizations need to have risk management in place as the world is now full of uncertainties that may affect their objectives, hence the risks are rising to the attempts toward such objectives. Most of them say that the logical choice is ISO 31000 as it is recognized by ISO (International Organization for Standardization), whereas the core principles of ISO 31000 is in line with the concept of Value Chain, i.e. Create and Protect Value. Besides, another reason put on the table is how ISO 31000 fits any regulations as it stands on the principles, applies generic framework, and adopts universal process, and so does COSO ERM. Despite its own respective merits of ISO 31000 and COSO, however, ISO 31000 adopters are more significant as the ISO 31000 has already been declared as the national standard of Indonesia by the National Standardization Agency of Indonesia (i.e., Badan Standardisasi Nasional Indonesia) known as SNI ISO 31000. 


\section{3rd International Conference on BUSINESS,}

The response from the FGD is in line with Dahms (2010) who stated that ERM is not only focused on the intuitive nature of risk management itself, but it also covers the scope that risk management delivers an added value to a company in regards to the aspect of cost-effective performance, resiliency, and competitive advantages through its existing business systems.

\section{The summarized answers of the interviews with practitioners}

Out of twenty companies as respondent, the number of ISO 31000 adopters or alike are much bigger than the number of COSO ERM adopters or alike, $70 \%$ and $20 \%$ respectively, whereas just two of them (10\%) said not clear whether to use ISO 31000 or COSO ERM. In this case, we put them into ISO 31000 as they adopt and reflect the process of AUS/ANZ 4360 which was the embryo of ISO 31000. Disregard the standard or framework or reference to the use, however, all of them said that ERM is a must and helpful to be competitive. The continuous use of ERM helps them know what risk factors lie in the whole value chain and, therefore, focus on what really matters to reduce the likelihood of potential risk events and the impact of such risk at its earlier stage. Reducing the risk means increasing the probability to achieve the objective, hence increasing the effectiveness of strategies, programs, and actions. Likewise, reducing the risk means reducing the cost, and reducing the cost mean higher efficiency. In short, increasing the effectiveness and higher efficiency is the key to a company's competitiveness in the market as they could bring a higher value proposition to their consumers.

\subsection{Results and Discussion of Question 4}

Question 4: What is the value of ERM to the longer term company's competitiveness? How it build the resilience and sustainability, especially when it relates to the VC model and LCC approach?

\section{The summarized answers of the FGD}

In this regard, the value of ERM is to help a company keep alerted both to the upside and downside risks related to their long-term goal and objective through its strategy. It means they must have set their risk appetite and then translated it down to its capacity and capability at a business process level, both to deal with today's challenges and to the future. The ERM will help organizations point out what is needed to have sufficient organizational's resilience against the turbulences as early as possible and then avoid the 


\section{3rd International Conference on BUSINESS,}

crisis to occur. It also helps the organization look ahead to what to embrace to be sustainable, as such of their value proposition and costing strategy and its operationalization through the VC model and LCC approach. This response also shared by Schiller \& Prpich (2014) who explained that the integration of risk management within the company enables them to increase the fluidity of the company's organizational process and knowledge in addressing the issue within its risks portfolio, the decision in regards to the cost-efficient risk management decision, and the interdependencies of risks. Consequently, to bring an added value to the company's long term competitiveness, the flow of information in regards to risks are needed to be maintained appropriately enabling the company to reap the benefits and the value of ERM in attaining or improving its competitiveness level, its capacity in managing risks and preventing a crisis from occurring.

\section{The summarized answers of the interviews with practitioners}

The value of ERM to the longer-term company's competitiveness is about the organization's culture. As such, we could build and sustain the right culture of ERM so that people in the company are alerted to their market dynamic through the VC model and be pro-active to translate such a dynamic into efficiency and effectiveness at the business process level through both VC model and LCC approach. Therefore, if we have ERM as a culture, the organization focus will not be only on operational, ad-hoc, and current issues but also beyond the horizon and strategically help the organization put their eyes over the longer term of company's competitiveness in the future. However, we need to add the VC model components and the LCC approach with more digital considerations such as blocked-chain, artificial intelligence, and data-driven decisionmaking process.

\subsection{Results and Discussion of Question 5}

Question 5: Since adopting VC model and LCC requires optimization at crosscutting business processes, what the contribution of ERM in this particular point of view?

\section{The summarized answers of the FGD}

The value creation indeed comes from the practice, and not from the concept and theoretical perspective. In this case, ERM helps and urges us to see the risk management 


\section{3rd International Conference on BUSINESS,}

integration at a business process level. As such, ISO 31000 explicitly says one of its 8 principles about integration. The principle of integration says that risk management is an integral part of all organizational activities (ISO, 2018). Hence, risk management must be integrated into and at the business process level and carried out by each organization's function.

Otherwise, risk management can be considered as an additional administrative task that does not create or protect value (Alijoyo, 2020). This response is in line with the research of Schiller \& Prpich (2014) and also related to the idea of risk maturity which explained that improving the company's risk management capabilities be addressed by improving the rate of vertical integration on all of the company's organizational function and increasing the company's risk knowledge. Therefore, This can reduce the likelihood of an inadequate risk management system and incoherent risk knowledge throughout all the company's management levels.

\section{The summarized answers of the interviews with practitioners}

Internalizing the principles of risk management as suggested in the ISO 31000, and then being adhered to their risk management framework and consistently apply the process of managing risks thoroughly as a culture will help the organization bring the optimization of the VC model and LCC approach both for making decision purpose, and putting them into action.

\subsection{Results and Discussion of Question 6}

Question 6: As we are now in the digital world, do you think ERM's role is still relevant for competitiveness of company that adopts a value chain (VC) model and life cycle cost (LCC) approach?

\section{The summarized answers of the FGD}

Yes, it is relevant as uncertainties and risks are rising in the digital world. They must be well-addressed explicitly and thoroughly by an organization that adopts the VC model and LCC approach. The supply chain of an organization has been radically changed both in its structure and elements due to digitalization where borderless and timeless are today's norm. This context is in line with the research conducted by Alter (2008) and Boyson (2014) who explained that the degree of risks and uncertainty are increasing with the advancement of technology. As such, the companies must adapt their digital supply 


\section{3rd International Conference on BUSINESS,}

chain to match the progression of technologies that have taken place. Consequently, the companies are introduced with the risks related to the issue of information, technologies, system reliability, cost minimization, and the applicability in using the established technologies to create and protect value for both the company and its customers.

\section{The summarized answers of the interviews with practitioners}

Yes, the role of ERM even becomes more critical and important in the digital world where the value chain becomes more data-driven. It has changed the structure of costs which has been swinging dramatically from brick-and-mortar value chain to the most online value chain paradigm. If the new paradigm is not well-addressed by an effective ERM, it could cause in an upside risk as well as in a downside risk. As a result, the exploration should be done at no time or at the same time with the elaboration, execution, and exploitation. Furthermore, since such upside and downside risk may travel much faster to become a problem and even a crisis or disaster, effective risk control is needed both in the decision-making process and at execution. In this regard, ERM helps the senior management of the company identify risks at its earliest, apply risk control proactively, and manage the risks swiftly both at the context of strategic level through VC model and at the details of operational level through such VC model and LCC approach.

\section{Conclusion, limitation, recommendation}

Since the future is more characterized by increasing volatility, uncertainty, complexities, and ambiguity (VUCA), the risks of doing business are also rising. Efforts to pursue competitiveness through the adoption of the VC model and LCC approach are also at risk as they are built upon assumption and visualization. To deal with and to gain the optimum value of the VC model, a company should be able to make their primary activities and supporting activities to help them exploit the upside risk and at the same time mitigate the downside risks. It requires a well-defined risk capacity, risk appetite, or risk tolerance to enable the company to exploit its upside risks ${ }^{1}$ and mitigate the downside risks ${ }^{2}$. As such, tools such as KRI are important and critically fundamental to sense proactively the need to reframe the visualization of the market dynamic and make necessary changes at an earlier stage.

The study discovers that the role of Enterprise Risk Management (ERM) using ISO 31000 is very important and required for the competitiveness of a company that adopts 


\section{3rd International Conference on BUSINESS,}

MANAGEMENT AND FINANCE

11-14 March, 2021

OXFORD, UNITED KINGDOM

${ }^{1}$ Upside risk is the risk the relates to the effect of uncertainties which could make organization fail to a achieve their objective to grab and/or exploit opportunity hence a failure to create value.

${ }^{2}$ Downside risk is the risk the relates to the effect of uncertainties which could make organization fail to achieve their objective to mitigate threats hence a failure to protect value.

the value chain (VC) model and life cycle cost (LCC) approach. Moreover, ERM is critically required due to many rising uncertainties and risks along with the value chain of the organization that needs to be identified, analyzed, evaluated, and treated accordingly and consistently through ERM. As such, ERM helps an organization to increase the organizational competitiveness by reducing the likelihood of an event risk which both will reduce the cost of operationalization and increase the capability and capacity of the organization to exploit the opportunity.

A limitation is noted; however, as no extensive empirical studies have been made except interviews with some practicing board members, hence, some empirical details might be overlooked and not well-covered. Therefore, future research is recommended to conduct such empirical studies by direct observation whereby we could expect a better understanding of the role of ISO 31000 based-ERM in leading to more effective adoption of the VC model and LCC approach to help companies build their competitiveness as expected today and forward.

\section{References}

Alijoyo, A. (2020). Enterprise Risk Management. Bandung: Center for Risk Management and Sustainability Indonesia.

Alter, S. (2008). Service system fundamentals: Work system, value chain, and life cycle. IBM Systems Journal, 47(1), 71-85. https://doi.org/10.1147/sj.471.0071

Anderson, S. W. (2006). Managing Costs and Cost Structure throughout the Value

Chain: Research on Strategic Cost Management. In C. S. Chapman, A. G.

Hopwood, \& M. D. Shields (Eds.), Handbook of Management Accounting

Research (Vol. 2, pp. 481-506). Elsevier.

https://doi.org/https://doi.org/10.1016/S1751-3243(06)02001-3

Arena, M., Arnaboldi, M., \& Azzone, G. (2011). Is enterprise risk management real?

Journal of Risk Research, 14(7), 779-797. 


\section{3rd International Conference on BUSINESS,}

MANAGEMENT AND FINANCE

11-14 March, 2021

OXFORD, UNITED KINGDOM

https://doi.org/10.1080/13669877.2011.571775

Asiedu, Y., \& Gu, P. (1998). Product life cycle cost analysis: State of the art review.

International Journal of Production Research, 36(4), 883-908.

https://doi.org/10.1080/002075498193444

Boyson, S. (2014). Cyber supply chain risk management: Revolutionizing the strategic control of critical IT systems. Technovation, 34(7), 342-353.

https://doi.org/10.1016/j.technovation.2014.02.001

Calatayud, A. (2017). The Connected Supply Chain: Enhancing Risk Management in a Changing World (No. IDB-DP-508). Washington DC: Inter-American

Development Bank.

COSO. (2004). Enterprise Risk Management - Integrated Framework. New York:

Committee of Sponsoring Organizations of the Treadway Commission.

COSO. (2017). Enterprise Risk Management - Integrated Framework. New York:

Committee of Sponsoring Organizations of the Treadway Commission.

Dahms, T. (2010). Resilience and risk management. Australian Journal of Emergency Management, 25(2), 21-26. Retrieved from

https://search.informit.org/doi/10.3316/INFORMIT.084576038154990

Dali, A., \& Lajtha, C. (2012). ISO 31000 Risk Management — "The Gold Standard." EDPACS, 45(5), 1-8. https://doi.org/10.1080/07366981.2012.682494

Frigo, M. L., \& Anderson, R. J. (2011). Embracing Enterprise Risk Management:

Practical approaches for getting started. New York: Committee of Sponsoring Organizations of the Treadway Commission. Retrieved from www.coso.org/documents/EmbracingERM-

GettingStartedforWebPostingDec110_000.pdf

Hoyt, R. E., \& Liebenberg, A. P. (2011). The Value of Enterprise Risk Management.

Journal of Risk and Insurance, 78(4), 795-822. https://doi.org/10.1111/j.15396975.2011.01413.x

ISO. (2018). Risk management - Guidelines. Geneva: International Organization for Standardization (ISO).

Knauer, T., \& Möslang, K. (2018). The adoption and benefits of life cycle costing. Journal of Accounting \& Organizational Change, 14(2), 188-215. https://doi.org/10.1108/JAOC-04-2016-0027

Korpi, E., \& Ala-Risku, T. (2008). Life cycle costing: a review of published case 


\section{3rd International Conference on BUSINESS,}

OXFORD, UNITED KINGDOM

studies. Managerial Auditing Journal, 23(3), 240-261.

https://doi.org/10.1108/02686900810857703

Kumar, D., \& Rajeev, P. V. (2016). Value chain: A conceptual framework. International Journal of Information Engineering and Management Sciences, 7(1), 74-77.

Lindberg, D. L., \& Seifert, D. L. (2011). Enterprise Risk Management (ERM) Can Assist Insurers in Complying with the Dodd-Frank Act. Journal of Insurance Regulation, 30(13), 319-337.

O'Donnell, E. (2005). Enterprise risk management: A systems-thinking framework for the event identification phase. International Journal of Accounting Information Systems, 6(3), 177-195.

https://doi.org/https://doi.org/10.1016/j.accinf.2005.05.002

Porter, M. E. (1998). Competitive Advantage: Creating and Sustaining Superior Performance. New York: The Free Press.

Purdy, G. (2010). ISO 31000:2009 - Setting a New Standard for Risk Management. Risk Analysis, 30(6), 881-886. https://doi.org/10.1111/j.1539-6924.2010.01442.x

Schiller, F., \& Prpich, G. (2014). Learning to organise risk management in organisations: what future for enterprise risk management? Journal of Risk Research, 17(8), 999-1017. https://doi.org/10.1080/13669877.2013.841725

Spira, L. F., \& Page, M. (2003). Risk management: The reinvention of internal control and the changing role of internal audit. Accounting, Auditing \& Accountability Journal, 16(4), 640-661. https://doi.org/10.1108/09513570310492335

Stabell, C. B., \& Fjeldstad, Ø. D. (1998). Configuring value for competitive advantage: on chains, shops, and networks. Strategic Management Journal, 19(5), 413-437. https://doi.org/10.1002/(SICI)1097-0266(199805)19:5<413::AIDSMJ946>3.0.CO;2-C 